\title{
Risk factors for eating disorders: investigating the relationships between global self-esteem, body-specific self-esteem and dietary restraint
}

\author{
Kavitha Dorairaj ${ }^{1 *}$, Kelly Thompson ${ }^{1}$, Simon Wilksch ${ }^{2}$, Tracey Wade ${ }^{2}$, Susan Paxton ${ }^{3}$, S Bryn Austin ${ }^{4,5}$, Sue Byrne ${ }^{1}$ \\ From 2013 ANZAED Conference: Inspiring Change: Person and Context \\ Melbourne, Australia. 23-24 August 2013
}

Low Global Self-Esteem (GSE) is a well-established risk factor for eating disorders. Whilst GSE may be defined as an overall evaluation of oneself, evidence suggests that self-esteem is a multidimensional construct involving the evaluation of specific facets of oneself. It is proposed that a Specific Self-Esteem will have stronger associations with a relevant behaviour than GSE. One example of a Specific Self-Esteem, Body-Specific SelfEsteem (BSSE), involves evaluating oneself in terms of body shape. This study investigated relationships between GSE, BSSE and dietary restraint (DR). It was hypothesised that BSSE would be more closely related to DR than GSE, and that the relationship between GSE and DR would be mediated by BSSE. Male $(\mathrm{N}=139)$ and female $(\mathrm{N}=133)$ adolescents, participants in the Prevention Across the Spectrum randomized control trial, completed the Rosenberg Self-Esteem Scale, genderspecific Body Dissatisfaction scales and the Restraint subscale of the Dutch Eating Behaviour Questionnaire at baseline. Results show that, for both genders, BSSE was more closely related than GSE to DR. In fact, among girls, there was no significant relationship between GSE and DR. Among boys, BSSE fully mediated the relationship between GSE and DR. Findings suggest that eating disorder prevention programs should prioritise targeting BSSE over GSE.

This abstract was presented in the Prevention stream of the 2013 ANZAED Conference.

\section{Authors' details}

${ }^{1}$ School of Psychology, The University of Western Australia, Australia. ${ }^{2}$ School of Psychology, Flinders University, Australia. ${ }^{3}$ School of Psychological Science,

\footnotetext{
* Correspondence: doraik01@student.uwa.edu.au

${ }^{1}$ School of Psychology, The University of Western Australia, Australia

Full list of author information is available at the end of the article
}

LaTrobe University, Australia. ${ }^{4}$ Department of Social and Behavioral Sciences, Harvard School of Public Health, USA. ${ }^{5}$ Division of Adolescent and Young Adult Medicine, Boston Children's Hospital, USA.

Published: 14 November 2013

doi:10.1186/2050-2974-1-S1-031

Cite this article as: Dorairaj et al: Risk factors for eating disorders: investigating the relationships between global self-esteem, bodyspecific self-esteem and dietary restraint. Journal of Eating Disorders 2013 1(Suppl 1):O31.
Submit your next manuscript to BioMed Central and take full advantage of:

- Convenient online submission

- Thorough peer review

- No space constraints or color figure charges

- Immediate publication on acceptance

- Inclusion in PubMed, CAS, Scopus and Google Scholar

- Research which is freely available for redistribution

\section{() Biomed Central}

